\title{
Beneficial Plant Growth Promoting Rhizobacteria in Rhizosphere, its Applications and Plant Growth: A Review
}

\author{
Ashiq Khan ${ }^{1,2^{*}}$, Muhammad Ishaq ${ }^{1}$, Anum Ali Ahmed ${ }^{1}$, Xusheng Guo ${ }^{1}$, Israr Khan ${ }^{3}$, Abdul Qadir Khan ${ }^{3}$ \\ ${ }^{1}$ Department of Life Sciences, Probiotics and Biological Feed Research Centre, Lanzhou University, Lanzhou, P.R. China \\ ${ }^{2}$ Department of Microbiology, Balochistan University of Information Technology Engineering and Management Sciences, Quetta, \\ Pakistan ${ }^{3}$ School of Life Sciences, Institute of Microbiology, Lanzhou University, Lanzhou, P.R. China
}

\section{Retraction Note:}

The article entitled "Beneficial Plant Growth Promoting Rhizobacteria in Rhizosphere, its Applications and Plant Growth: A Review", has been accepted for publication in the Journal of Natural Products Chemistry \& Research: Current Research considering the statements provided in the article as personal opinion of the author which was found not having any conflict or biasness towards anything. As the article was a perspective one, information provided by the author was considered as an opinion to be expressed through publication. Publisher took decision to make the article online solely based on the reviewer's suggestion which considered the article not but a personal opinion of the author. However, it is found that the author has some personal concerns and issues, therefore, being retracted from the journal.

Correspondence to: Ashiq Khan, Department of Life Sciences, Probiotics and Biological Feed Research Centre, Lanzhou University, Lanzhou 730000, P.R. China, Tel: +86931891 1119; E-mail: Ashiq2017@lzu.edu.cn

Received: February 28, 2019; Accepted: April 18, 2019; Published: April 27, 2019 